\title{
An Empirical Study of Chinese EFL Learners' Understanding and Translation of Expressions of Multiplication Entailing "Times"
}

\author{
Jing $\operatorname{Li}^{1}$ \\ ${ }^{1}$ School of Foreign Languages and Literature, North China Electric Power University, Baoding 071000, China \\ Correspondence: Jing Li, School of Foreign Languages and Literature, North China Electric Power University, \\ Baoding, Hebei Province, China.
}

Received: April 21, 2020

Accepted: May 14, 2020

Online Published: May 15, 2020

doi: 10.5539/elt.v13n6p58

URL: https://doi.org/10.5539/elt.v13n6p58

\begin{abstract}
The debate on how to understand such expressions of multiplication entailing "times" as " $n$ times more than" and "increase (by) $n$ times" has been on and off in China since the 1980s. A review of literature seems to suggest that despite early-stage divergence in understanding, there is a general consensus among the Chinese academia at present that the English word "times" entails the base number, and therefore expressions of multiplication like "n times more than" and "increase (by) $n$ times" are equivalent to the expression " $n$ times as much/many as". This paper intends to find out whether this consensus is reflected in Chinese EFL learners' understanding of those expressions. Altogether 16 English majors from one of the key universities in the northern part of China were tested on their understanding and translation of two passages with embedded arithmetic comparisons using " $n$ times more than" and "increase n times" respectively. It is found that a sizable proportion of them $(62.5 \%$ for the former and $56.25 \%$ for the latter) gave inaccurate translation and that their rendering manifests not only their misunderstanding but also indiscretion in the translating process. Such factors as students' indiscriminate use of information from the Internet, ambiguity and errors in popular grammar books, the presumed disjunction between EFL research and EFL teaching, and the untimely updating of English competence on the part of Chinese EFL teachers in China are proposed as possible reasons.
\end{abstract}

Keywords: ambiguity and errors in popular grammar books, disjunction between EFL research and EFL teaching, expressions entailing "times", students' indiscriminate use of information from the Internet

\section{Introduction}

Pennington (2002) defines grammar as "nothing more or less than the organizing principles of a linguistic or (broader) communicational system, without which, there is no system". Despite that, the English language has not been without grammatical controversies. Joe Trotta (2010), citing several examples of non-standard English like unusual usages ("like" used as a conjuncture, e.g.), neologisms and catchphrases from Popular Culture, asserts that those usages labeled as non-standard are regarded as "a reflection of bad character and poor education", which Joe considers as harmful because it inhibits a better understanding of the evolution of the English language.

The expression " $n$ times more than" have aroused a similar response in English-speaking countries. People are divided either in the validity or in the understanding of this expression. Not a few people disapprove of this expression. American lexicographer and teacher Bryan A. Garner (2016) in Garner's Modern English Usage puts "times more than" in the entry on "illogic" to explain the unacceptability of an illogical phrase in the English language. Statistical literacy advocate Milo Schield (1999), in his article "Common Errors in Forming Arithmetic Comparisons", points out people's wrong equation of "times as much" and "times more than", and asserts "If B is three times as much as A, then B is two times more than A." In Quora, a famous Q\&A platform, under the question "Do 'three times bigger' and 'three times as big as' have the same meaning?", a variety of answers coexist, some taking sides with the "yes" camp and others the "no" camp. A seemingly wise approach proposed by some is to avoid using the ambiguous expression once and for all. However, a simple search in Corpus of Contemporary American English(COCA) shows that the combination "times more than" is used 521 times, "times as much as" 338 times, and "times as many as" 124 times. Therefore, it is unrealistic to turn a blind eye to the prevalent use of this expression. 
The prescriptive nature of language necessitates that a uniform understanding should be attempted to avoid misunderstanding. Perhaps to respond to Garner's labelling the expression as illogic, Merriam-Webster usage dictionary says, "mathematics and language are two different things, attempting to apply mathematical logic to the study and understanding of language is, in fact, illogical." As a matter of fact, such authoritative dictionaries as Merriam-Webster's Advanced Learner's Dictionary and Cambridge Advanced Learner's Dictionary have very lucid paraphrasing like "She earns five times as much as I do. / She earns five times more than I do." This kind of prescription helps to crystallize the usage of the word "times". It should be accentuated that dictionaries should have the final say in time of confusion.

With the advent of globalization and China's fast stepping into the world market, English has become almost a necessity for anyone in China who wants to strike up and maintain a relationship with people from English-speaking countries economically, culturally or politically. For Chinese English learners, dictionaries, grammar books, English teachers and all kinds of reference books are often reliable sources for the clarification of doubts. However, maybe an echo of the above mentioned controversy in English-speaking countries, expressions entailing the use of the word "times" have been interpreted differently, which has drawn considerable attention from the academia in China since as early as the $1980 \mathrm{~s}$.

The earliest journal article dealing with this problem appeared in 1982 in the journal of Foreign Language Teaching (one of the core journals in foreign language teaching research in China). It was written by Zhongchi Zeng(1982), who claims that the sentence "This room is three times larger than that one." equals "This room is four times as large as that one." Ever since then, according to the CNKI, one of the most frequently used academic databases in China, more than two dozen papers have been published in China, with the latest one published in the year 2016(See the metrological visualization analysis in Figure 1).

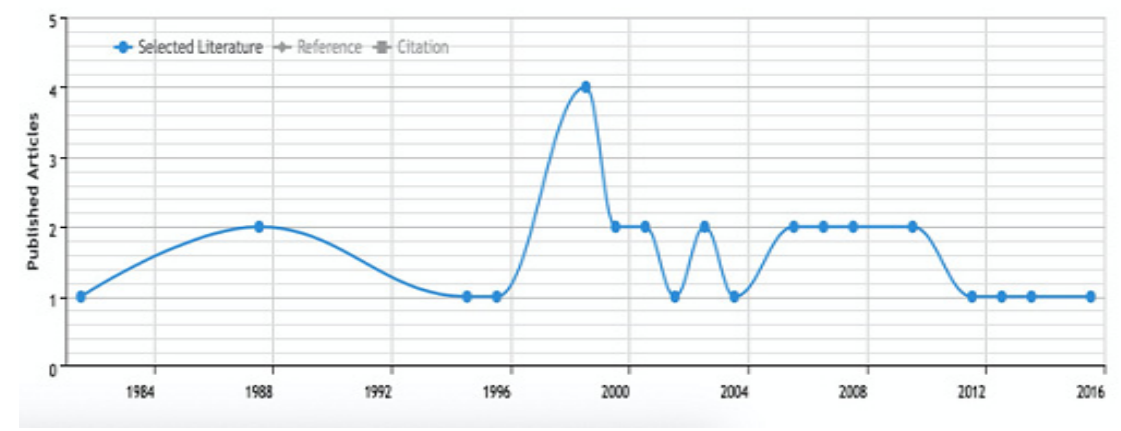

Figure 1. Metrological visualization analysis of relevant literature (provided by CNKI)

A review of literature manifests that a succession of Chinese scholars contradict Zhongchi Zeng by either using English native speakers as a reference or using authoritative scientific sources or using both, and come to the conclusion that "n times more than" is synonymous with "n times as many/much as" (Hongdang Meng, 1996; Changsheng Li, 2003; Feng Miao, 2006). Despite the fact that occasionally there are journal authors who give inconsistent and self-contradictory interpretations, making it all the more confusing for readers, it seems that at present there is a general consensus among the academia that the English word "times" entails the base number, and therefore expressions of multiplication using " $n$ times more than" and "increase (by) $n$ times" are equivalent to the expression "n times as much/many as".

The matter appears to have been settled. However, ever since I embarked on my teaching career in 2008, I have been constantly bothered by the substantial number of students who seem to be strangers to the equivalence between the several aforementioned arithmetic expressions. So far, there has been no empirical study of Chinese EFL learners' understanding of those arithmetic expressions entailing "times". Realizing that misinterpretation of these expressions could lead to misunderstanding even disputes among Chinese English speakers and native English speakers, I was motivated to explore this issue and find out whether or not language research and teaching are seamlessly joined together.

\section{Method}

\subsection{Participants}

Altogether 16 English majors from one of the key Chinese universities in the northern part of China were recruited. The university is known to have cultivated a substantial number of English major graduates. It is 
required that the participants have passed TEM 8 with at least B+ scores. TEM 8 , standing for Test for English majors (Grade 8), is the highest-level comprehensive proficiency test for English majors in China, who are supposed to take and pass this test in the fourth year at university. According to statistics, the national pass rate for the year 2019 is $47.33 \%, 35.78 \%$ for the year $2018,37.65 \%$ for the year 2017 , which is indicative of the stringent level of this language test. B+ scores are scores above 70 (The full score is 100) and signify upper-intermediate or advanced level of English proficiency. All the participants were recruited and filtered by the researcher in accordance with required qualifications.

\subsection{Materials and Procedures}

In order to accurately measure the participants' understanding of the several arithmetic comparison expressions already mentioned, I chose two short passages (See below) for them to translate into Chinese.

Passage one: The council votes to raise pay by nearly 48 percent, to $\$ 32473$ from $\$ 22000$. The increase was roughly three times more than the 15 percent raise the Elected Officials Compensation Commission had recommended. (Source: Atlanta Journal Constitution)

Passage two: The iron and steel production would be increased roughly eight times. That is, as against production in 1958 of 500000 metric tons of pig iron and 410000 metric tons of steel, the program's target is 4000000 metric tons of pig iron and 3000000 to 3500000 metric tons of steel. (Source: Changsheng Li, 2003)

All the participants were asked to translate the two passages on designated computers with the assigned duration of 20 minutes. I used a software program known as Camtasia, which can capture and record images from the participant's computer desktop, to record the participant's translation work. This enabled the researcher to see clearly the translation process.

After they were finished, I administered a semi-structured interview in Chinese. The questions I asked include:

1. Why did you translate the arithmetic comparisons as such?

2. Did you use the specific figures in the passages to assist you in the translation process?

3. When grammatical doubt occurs in your everyday English study, how do you resolve it?

The participants' verbal responses were first recorded by the audio mode of Camtasia and then transcribed. This part was used to ask them to clarify the translation process.

\section{Results}

All of the collected data were analyzed in relation to the participants' translation of relevant expressions of multiplication. Therefore, I mainly focused on their rendition of "three times more than" and "increased roughly eight times". In addition, I also examined their use of the context in the translation process.

\subsection{Participants' Translation of "Three Times More Than"}

Of all the participants, 6 of them (37.5\%) translated this expression correctly while the other 10 participants $(62.5 \%)$ invariably considered it equivalent to "four times as much as" and therefore gave incorrect translation.

\subsection{Participants' Translation of "Increased Roughly Eight Times"}

Of all the participants, 7 of them (43.75\%) translated this expression correctly while to the other 9 participants $(56.25 \%)$, this expression equaled "nine times as much as" and thus gave incorrect translation.

\subsection{Participants' Utilization of the Specific Figures in Revising Translation}

When asked whether they used the figures in the passages to assist them in the translation process, 3 of them $(18.75 \%)$ answered in the affirmative. As is confirmed from their translating process recorded by Camtasia, of all the 7 participants who translated "increased roughly eight times" correctly, 3 of them drew hints from the figures provided and revised their otherwise incorrect understanding. For the 9 participants who translated this phrase incorrectly and didn't utilize the arithmetic relations between the specific figures provided, they said that time constraints didn't allow them to pay more attention to the figures in the passage.

\subsection{Participants' Reply to Why They Translated as Such}

When asked why they translated those expressions as such, those participants who translated wrongly said what they have learned both inside and outside the language classroom made them believe that expressions of multiplication entailing "times" do not include the base number. They explained by saying that "My English teacher (Chinese EFL teacher) taught me so." or "I looked them up in my grammar book and was told so." By contrast, those students who translated the expressions correctly without utilizing the arithmetic relations 
between the specific figures said that they had observed the contradiction between different sources, and thus they consulted different sources and obtained 'authoritative' understanding.

\subsection{Participants' Solution to Their Grammatical Doubt in Everyday Study}

All participants said that in everyday English study, they would encounter numerous difficulties. As for their solution, the three primary channels in descending order are the Internet, grammar books, and their Chinese EFL teachers. Almost all participants said normally for the sake of convenience, they would use search engines to find answers and explanations.

\section{Discussion}

The participants' performance is both frustrating and disturbing. To begin with, their misunderstanding of the several expressions of multiplication under discussion unequivocally indicates grammatical incompetence in this regard. Their disregard for the context, specifically the concrete figures in the passage, displays a lack of discretion which is a must for good and qualified translators. In addition, since the participants represent upper-immediate or even advanced level of English competence, their performance seems to be sending a piece of evidence that the cultivation of specialists in English does not live up to expectations, which has become vocal criticism in Chinese academia in recent years. What is even more troubling, when English majors graduate, they enter into the workforce, working as language service providers in government sectors, private sectors, education institutions or foreign companies. Inevitably they will deal with arithmetic comparison expressions under discussion. Their inaccurate translation will result in the tarnishing of the education they have received if pointed out or lead to misunderstanding even disputes if overlooked.

The three primary channels the participants reported when they are in doubt may shed light on the reasons for their performance. The often-used tool is search engines where they type in their doubts and relevant answers, if any, will be searched and displayed instantly for them to view, or they can ask questions and wait for answers. The most popular and widely-used search engine in mainland China is Baidu, which has a Q\&A platform named Baiduzhidao and operates like Quora. However, the Internet is a place where anyone can voice his/her opinion, whether it be authoritative or misleading. Therefore, a miscellaneous and even contradictory range of answers juxtapose on the Internet. One of the most irritating scenarios an English teacher can encounter is when a student refutes him/her by saying "This is what is said on the Internet" without providing authoritative or reliable sources of information. Type in the search box of Baidu "the relationship between three times more than and three times as much as", and one will find a large number of self-appointed English specialists who claim quite arbitrarily or incoherently that they are different. Of course, there are correct answers and explanations, which are often drowned in the sea of misinformation, making it difficult for views to distinguish.

A more reliable and authoritative source is English grammar books. However, even those books are not necessarily without erroneous interpretation. Take Daozhen Zhang English Grammar (the 2008 Edition) as an example. This grammar book is touted as "popular nationwide, marketable for ten years with a readership of 80 million EFL learners" on its cover. I often consult it in times of confusion. Open this grammar book, and I find the following examples with their Chinese translations provided.

This house is ten times bigger than that one. (这座房子比那座大十倍。)

He has read three times more books than I have. (他读过的书是我读过的三倍。)

Both of these two examples are used to illustrate the structure "n times more than". It is explicit from the Chinese translations that the compiler of this grammar book has given conflicting translations which represent confused understanding, with the first translation meaning "This house is eleven times as big as that one" and the second translation meaning "He has read three times as many books as I have." What is discouraging is that the 2012 Edition of this grammar book doesn't get corrected in this aspect.

Then I opened another popular grammar book written by Yi Liu, Treasury of English Grammar. Surprisingly, under the subheading "Common Expressions of Multiplication", there is no touching upon of " $\mathrm{n}$ times more.... than". Encouragingly, the several editions of grammar book compiled by Bing Bo, which I gain access to, all provide accurate and consistent interpretation.

Besides grammar books, many learners of English also consult translation textbooks or exercise books. Translation is a highly specialized and demanding activity. The translation of figures and statistics needs to be $100 \%$ correct. However, flip through translation books, and it is not difficult to find wrong translations of the several expressions of multiplication mentioned above, which is very misleading for their readers. 
Arguably, grammar books and translation books have seen considerable improvement in quality over the years. But one troubling fact is that those imperfect books are still in circulation, stored and consulted either in public or private libraries.

Chinese EFL teachers are who EFL learners trust beyond doubt and usually turn to when learning difficulties surface, especially when they are receiving regular education. I remember when I was studying at a key university in China as an English major in the first several years of this $21^{\text {st }}$ century, my Chinese EFL teachers invariably told me to the effect that "This house is ten times bigger than that one." equals "This house is eleven times as big as that one" and that in the expression "increase n times", "n times" does not entail the base number. I guess my teachers, mainly born in the 1960s and 1970s, for one reason or another, did not get round to updating the grammatical knowledge they had received in the 1980s.

As for the participants of my study, it is quite explicit from the interview that some of their Chinese EFL teachers have erroneous understanding themselves and pass down their knowledge to their students. It may be presumed that not a few Chinese EFL teachers, whether he/she be teaching beginners, intermediate or advanced learners, are unaware of the controversy involving the use of those arithmetic expressions. The participants' performance may have illustrated this point. It may be further presumed that many Chinese EFL teachers are not so well-informed about the new trends in the academia, presumably because they do not read EFL teaching and research journals. This situation may have been confounded by both Chinese EFL teachers' and EFL learners' contact with native speakers of English, who not necessarily approve of the standard usage prescribed.

It should be pointed out here that although dictionaries provide authoritative explanations of meaning, not all the dictionaries Chinese EFL learners have access to provide the usage of "times" as clearly as they should. Longman Dictionary of Contemporary English and The Oxford English-Chinese Dictionary are cases in point. This may account for why the participants do not consult dictionaries when they encounter what they consider as grammatical issues.

\section{Conclusion}

This study investigates Chinese EFL students' understanding and translation of two passages with embedded arithmetic comparisons using " $n$ times more than" and "increase $n$ times" respectively. It is found that a sizable proportion of them gave inaccurate translation and their rendition manifests not only their misunderstanding but also indiscretion in the translating process.

It is quite deplorable that the grammatical controversy that surfaced in the $1980 \mathrm{~s}$ and seems to have been resolved in the past twenty years in Chinese academia is not over, lurking on the Internet, in various grammar books and translation textbooks, and in English classrooms. It is high time that a homogenous understanding of those expressions of multiplication should be achieved. This can be achieved in the following activities.

To begin with, Chinese EFL teachers at different levels of education should be trained to gain correct understanding. This may be achieved in language workshops aimed at updating and improving their grammatical and lexical proficiency. Besides, students should be taught to view critically what he/she finds on the Internet, in books or in class. Finally, both teachers and students should be aware that to keep informed, they should read English teaching journals on a regular basis.

Regarding some limitations of this study, further study is necessary.

First, this study investigated only a small number of students with upper-intermediate to advanced levels of language proficiency from one university in one Chinese city. To confirm the conclusion of this study, further studies are needed to investigate a broader representation of English majors with more diverse levels of language proficiency from different parts of China. Non-English majors should also be investigated in this respect to generalize the conclusion of the current study.

Second, Chinese EFL teachers in China are not involved in this study. Further studies can involve teachers at different levels of education, test them on their understanding of the arithmetic expressions under discussion, and study the ways in which they upgrade their English knowledge base. Their voices may offer really practical solutions to improving the current situation.

The present study sheds light on the disjunction between EFL research and the actual EFL teaching effect in China. It is proposed that further studies would extend this study, aiming at bridging the gap.

\section{Acknowledgements}

This research was made possible through North China Electric Power University Teaching Support Program awarded to excellent young faculty. 


\section{References}

Garner, B. A. (2016). Garner's modern English usage. Oxford University Press, xxiii. https://doi.org/10.1093/acref/9780190491482.001.0001

Li, Ch. Sh. (2003). Clearing up fallacies over expressions of "Times". Journal of Nanjing University (Philosophy, Humanities and Social Sciences), 40(5), 111-114.

Liu, Y. (2009). Treasury of English grammar. Beijing: Foreign Language Teaching and Research Press, 248.

Meng, H. D. (1996). Several issues with the translation of multiplication expressions in translation monographs. Chinese Translators Journal, 6, 32-34.

Miao. F. (2006). Discerning from the translation of multiplication expressions the differences between Chinese and English thinking. Chinese Translators Journal, 4, 70-73.

Pennington, M. (2002). Grammar and communication: new directions in theory and practice. In E. Hinkel and S. Fotos, (Eds.), New perspective on grammar teaching in second language classrooms. Mahwah, NJ: Lawrence Erlbaum Associates, 77-98.

Schield, Milo. (1999). Common errors in forming arithmetic comparisons. of Significance. The Association of Public Data Users, Volume 1.

Trotta, J. (2010). Whose rules rule? grammar controversies, popular culture and the fear of English from below. Nordic Journal of English Studies, 9(3), 41-65. https://doi.org/10.35360/njes.229

Zeng, Zh. Ch. (1982). Several issues with "times and twice" in English teaching and translation. Foreign Language Teaching, 4, 27-30.

Zhang, D. Zh. (2008). Daozhen Zhang English grammar. Jinan: Shandong Science and Technology Press, 230-231.

\section{Copyrights}

Copyright for this article is retained by the author(s), with first publication rights granted to the journal.

This is an open-access article distributed under the terms and conditions of the Creative Commons Attribution license (http://creativecommons.org/licenses/by/4.0/). 